\title{
Modelling Catchments in Qatar to Assist in Operations
}

\author{
Shirish Gokhale \\ sgokhale@ashghal.gov.qa \\ Public Works Authority (Ashghal), Doha, Qatar \\ Anil Kumar Gupta \\ agupta@ashghal.gov.qa \\ Public Works Authority (Ashghal), Doha, Qatar \\ Nasser Yousef Fakhroo \\ nfakhroo@ashghal.gov.qa \\ Public Works Authority (Ashghal), Doha, Qatar \\ Kapil Devang \\ kdevang@ashghal.gov.qa \\ Public Works Authority (Ashghal), Doha, Qatar \\ Tim Kelly \\ tkelly@ashghal.gov.qa \\ Public Works Authority (Ashghal), Doha, Qatar
}

\begin{abstract}
Qatar is experiencing unprecedented growth and infrastructure is being developed at a rapid pace. The infrastructure is served by storm water systems which are under development and need to be resilient in case of storms. The storm water systems serving Doha and nearby areas are complex in nature. They include passive, positive drainage systems and also connect critical locations such as underpasses and a number of ancillaries. The two main reasons adding to the complexity are asset creation work ongoing at multiple locations and various temporary and permanent systems operating simultaneously. A standardized approach for operating this complex storm drainage network becomes essential. Also, while solving problems such as flooding during a rainfall event, at times root cause of a problem may be at a different geographical place than that of the actual location of the problem. It is difficult to arrive at a root cause without an overall understanding of the system. This along with a standardized approach is useful in taking better informed decisions before, during and after storm events. A coordinated effort between Ashghal Design and Operation \& Maintenance Departments resulted into an operational philosophy. Hydraulic modelling supported by comprehensive GIS information played an important role in developing this. The work consisted of considering issues encountered during recent major storm events and simulating multiple scenarios. The recommended actions are currently under implementation. The next stage will be to set up a near real time operation system which would include SCADA data linked to and hydraulic models.
\end{abstract}

Keywords: Reclaimed asphalt pavement; Mix design; Rutting; Fracture; Optimum RAP content

\section{INTRODUCTION}

The State of Qatar has experienced exceptional levels of economic and population growth over the past three decades. Exponential increase has been observed in last two decades. Population has grown from 700,000 in year 2000 to 2.5 million currently. Figure 
1 shows the population increase over the years (United Nations, 2017). This population growth has translated into an ever-increasing demand for housing, commercial, institutional and recreational development. Rapid growth in the infrastructure has changed the urban landscape drastically. Open land which was relatively permeable has been converted into a built-up area with high impermeability (Shandas et al., 2017). This has resulted into changed runoff patterns.

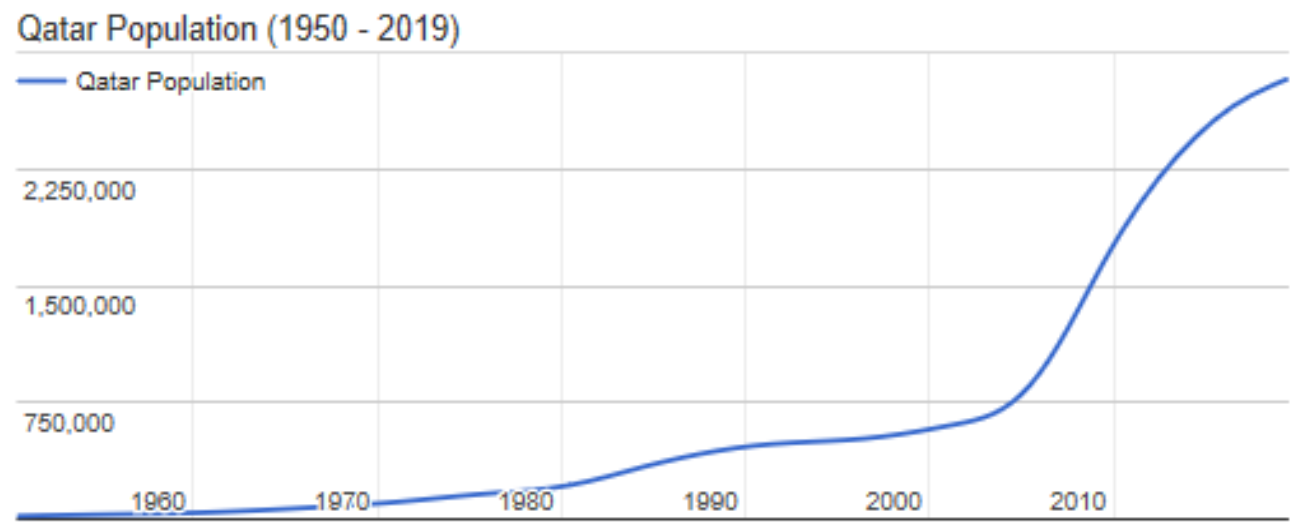

Figure 1: Population growth (data source: 2019 United Nations, DESA, Population Division)

Urban flash floods can be devastating for the population, assets and can bring a city to standstill. The storm water systems are not currently proportionately developed to cater to such events (Salvan, et al., 2016). Frequency of floods has increased in recent years in Qatar primarily due to an increase in the frequency of occurrence of extreme storm events. Real Time Controlled (RTC) operations have been tested with multiple approaches all over the world (Jafari et al., 2018). There is therefore a strong need to optimize current assets for changed rainfall and rapid development scenarios.

This paper focusses on hydraulic model developed to represent ever changing existing storm water systems and its use for understanding current and future performance issues and identifying mitigation measures. The model uses design storm events as well as measured rainfall events. It was further used to develop an operational philosophy for planning and optimizing the level of service.

\section{STORM WATER MANAGEMENT SYSTEM IN QATAR}

Storm water catchments in Qatar comprise of three main areas:

- $\quad$ Asian Games Outfall (AGO) \& Musaimeer Pump Station Outfalls (MPS).

- $\quad$ North District of Doha (NDoD - including Lusail and West Bay).

- Wakra (includes southern areas).

The NDoD and Wakra catchments are under the subject of separate detailed outfall studies and drainage strategies for these catchments will be developed in the next two years. Currently there are a few outfalls including AGO operational. The Musaimeer tunnel has been constructed and a terminal pumping station is under construction. Figure 2 shows storm water catchments in Qatar. 


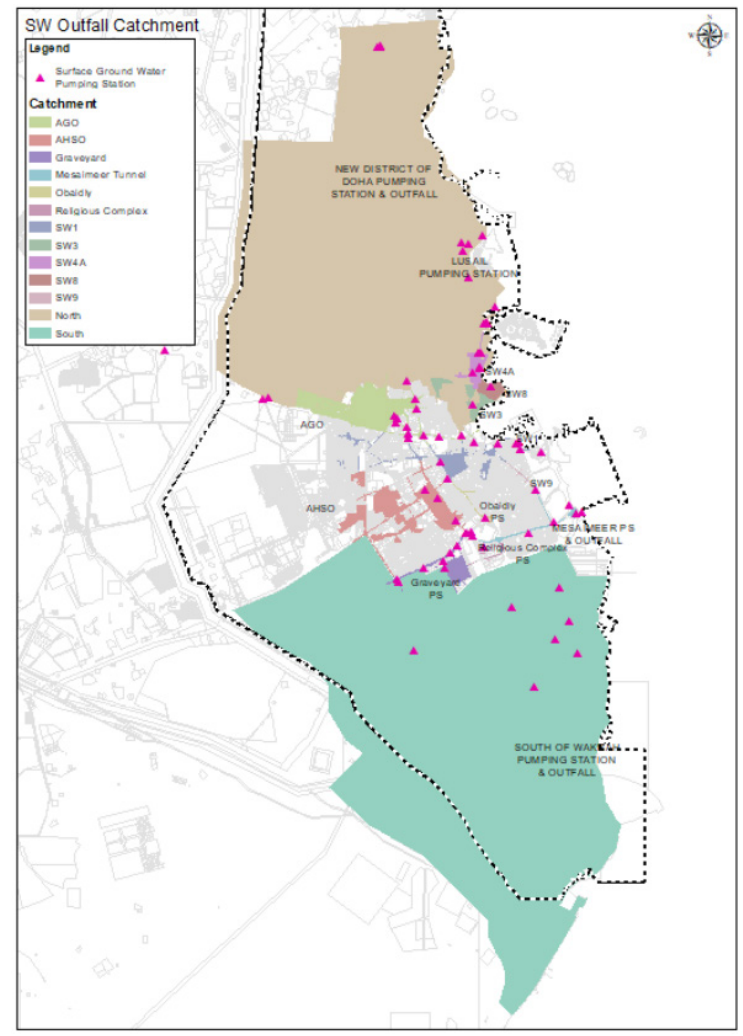

Figure 2: Storm water catchments in Qatar and locations of pumping stations

There are two main types of surface water collection and disposal systems in Qatar:

\subsection{Piped systems}

This type of system is known as a positive system in Qatar. The main principle of the positive drainage system is to remove rainwater as quickly as possible from where it falls. Surface water from certain paved and roof areas is collected and directed straight into an underground network of pipes to convey the water by gravity to a disposal point. These disposal points are currently either the marine environment or inland emergency flood areas.

\subsection{Passive systems}

These are full or partial infiltration drainage systems which help manage surface water by replicating natural drainage. A network of infiltration trenches decreases the rate at which water drains by storing and infiltrating or releasing at a controlled rate. This is typically designed for return periods up to 10 years. During extreme events capacity is exceeded and runoff is conveyed through overland flow paths.

\subsection{Challenges in level of service}

Both the systems have a finite capacity which, if exceeded, will cause the system firstly to surcharge and ultimately overflow and cause flooding. Subsequent infill development 
or redevelopment/expansion of urban areas that replaces permeable ground results in increased peak flows and the potential need to upsize the drainage system to continue to provide the prescribed level of service.

As the permanent measures are being constructed e.g. the terminal MPS, there is a need to address storm water in the interim. There are major areas connected to the tunnel and runoff from these areas needs to be managed till the MPS is operational. There are also a number of other construction projects ongoing at various stages of execution. Interim measures are required to manage storm water from these areas.

Increased ground water levels have posed a challenge in some areas making the passive systems ineffective.

While solving flooding problems, at times root cause of a problem may be at a different geographical location than that of the problem. It is difficult to arrive at a root cause without an understanding of the overall system.

\section{HYDRAULIC MODELLING}

A surface drainage includes underground positive/ passive systems as well as overland flows. Interaction between underground (1D) and overland (2D) flows is complex. This can be reasonably modelled during normal storms, however, during extreme events to understand how the overall system works, can be challenging due to operational issues such as clogging of gullies and blockages. The complexity is further increased by the features on ground such as buildings, walls, sidewalks and curbs etc.

Comprehensive Geographic Information System (GIS) data which includes asset data and LiDAR digital terrain models, was processed and used for building 1D-2D catchment models. Assets in ground were modelled using InfoWorks ICM. There are a number of temporary measures taken till permanent measures become fully operational. These include pumps and emergency flooding areas or lagoons and storages. These were included in the model to represent the current catchment. Details were included in the model for overland features around critical locations such as underpasses.

The catchment models were calibrated based on flow and depths survey data and information available in SCADA records.

\section{RESULTS}

The models were simulated for 5, 10, 25, 50 and 100 year design storm events as well as recorded storm events that occurred in the year 2018. The results were validated for various areas based on historical flooding records, flood extents and operations feedback. Mitigation measures were identified for priority areas and where permanent measures will be in place in future.

An operational philosophy was derived with the help of the models. This included works to be done when there is business as usual, during storm event alert status, during storm and after a storm event. This helps in optimizing the existing network including storages to get maximum level of service in the interim and longer-term scenarios making it more sustainable.

Figure 3 shows examples of model results where the model shows good representation of flood paths, extents and potential low-lying areas needing attention. Example results also show a tunnel top water level during a real time operation scenario. 
Improved understanding of the system using detailed models helped in identification of controls in the AGO - MPS catchment which would help in optimizing the system operation in ever changing short term as well as long term scenarios. Figure 4 shows the locations of flow controls.

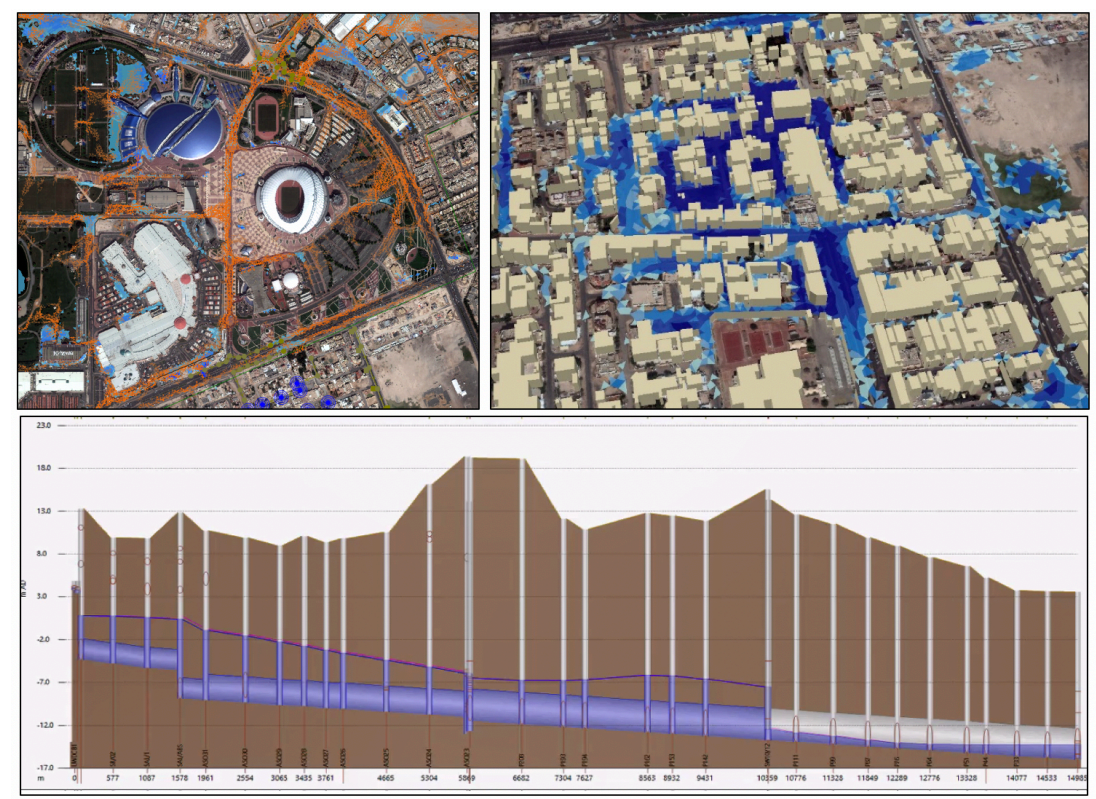

Figure 3: Examples of model results showing overland flow paths, flood depths and underground tunnel hydraulic performance

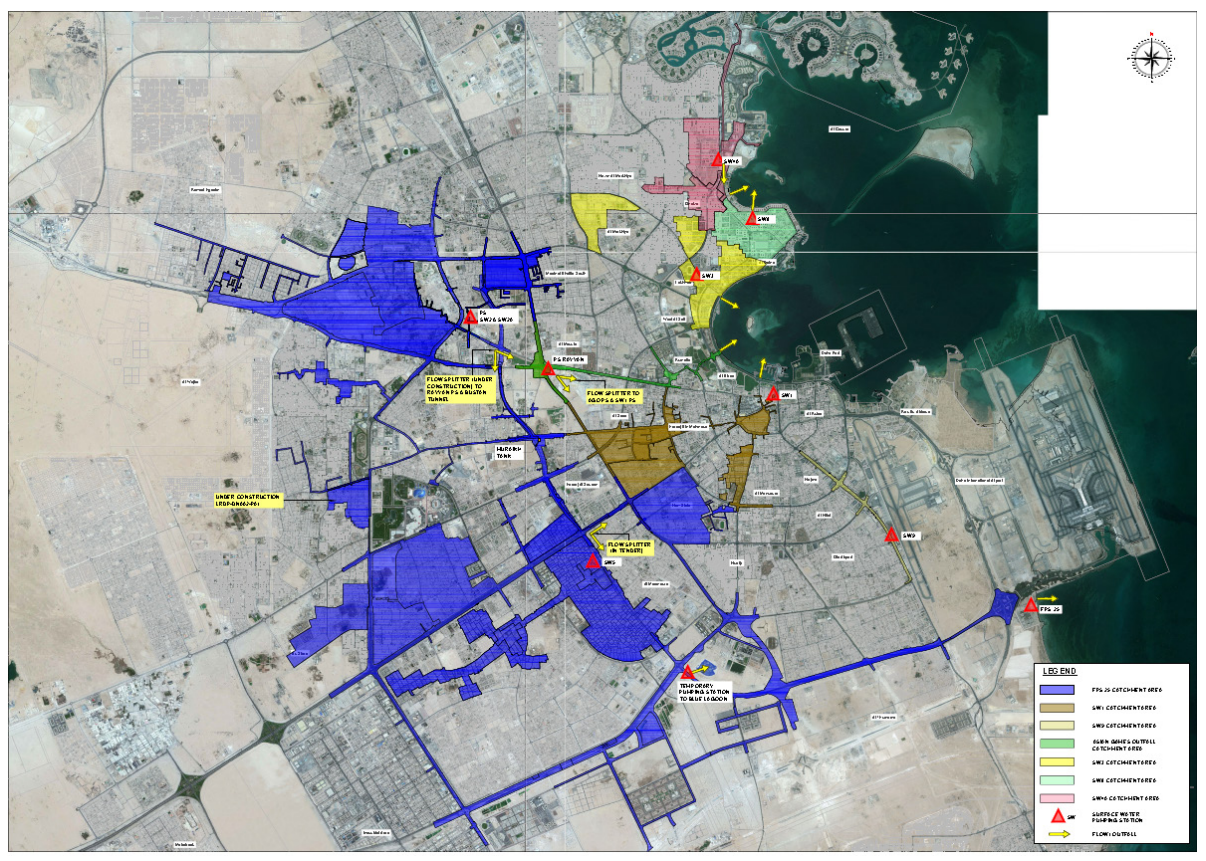

Figure 4: Locations of controls identified in the catchments for optimized operation 


\section{CONCLUSION}

Rapid pace of development in Qatar along with a significantly changed rainfall pattern has posed a major challenge in terms of managing storm water. Due to the evolving storm-water network, there are a number of temporary and permanent systems operating that play a major role in storm water management in Qatar. A dynamic hydraulic model was prepared and maintained in InfoWorks ICM to help in decisions and to plan temporary and permanent flood mitigation measures. The model was simulated for a number of scenarios and locations of flow controls were identified. This was used in defining operational procedures which would help in sustainable and optimized use of existing infrastructure in ever changing short term scenario and the long term as well. The system is evolving and the set philosophy is under implementation. The next stage of this is the near real time decision making involving a link with SCADA data.

\section{ACKNOWLEDGMENT}

Authors would like to thank the Ashghal Drainage Networks Operation and Maintenance Department for their inputs in preparing the model and operational philosophy. Authors would also like to thank the Ashghal Engineering Services Department and Ministry of Municipality and Environment for supplying the LiDAR data.

\section{REFERENCES}

Jafari, F., Mousavi, J. \& Joong, K. (2018). A Real-time Optimal Gate Operation Model for Urban Drainage Systems. 10.29007/ktzw.

Salvan, L., Abily, M., Gourbesville, P. \& Schoorens, J. (2016). Drainage system and detailed urban topography: Towards operational 1D-2D modelling for storm water management. Procedia Engineering, 154. 890-897. 10.1016/j.proeng.2016.07.469.

Shandas, V., Makido, Y. \& Ferwati, S. (2017). Rapid urban growth and land use patterns in Doha, Qatar: Opportunities for sustainability. European Journal of Sustainable Development Research, 1(2), 11. DOI: 10.20897/ejosdr.201711.

United Nations (2019). DESA, Population Division, World Population Prospects. 